\title{
DOCUMENTOS
}

\section{"Resonancias de la modernidad" \\ Festival de Música Contemporánea en Buenos Aires}

\author{
por \\ Miguel Letelier Valdés \\ mileval@vtr.net \\ Facultad de Artes, Universidad de Chile, Chile
}

Con el alto auspicio de la Secretaría de Cultura de la Presidencia de la Nación y en la representación de este organismo, el Secretario de Cultura Jorge Coscia, junto al Director Nacional de Artes José Luis Castiñeira de Dios y el organizador y Director del Festival Eduardo Kusnir, se ha realizado en la Ciudad de Buenos Aires, entre los días 16 y 25 de junio de 2011, el Festival denominado "Resonancias de la modernidad", en conmemoración de los 50 años de la puesta en marcha del Instituto del Centro Latinoamericano de Altos Estudios Musicales Torcuato di Tella (CLAEM), fundado por el maestro (QEPD) Alberto Ginastera el año 1971.

No es común en nuestra latinoamérica que el Estado desembolse semejantes cantidades de dinero -aunque sigan siendo ínfimas de todas maneras en relación con otros gastos- en un Festival cuya excepcional organización no escatimó pagos en pasajes, hoteles, traslados, comidas, etc. La presentación gráfica se materializó en un magnífico libro de lujosa impresión, en el cual se describe la fecunda y a la vez azarosa trayectoria del CLAEM. Esta publicación contiene opiniones y puntos de vista, artículos, memorias, descripciones, fotografías de los diferentes compositores y becarios, currículum de cada uno de los que aportaron con su trabajo al Instituto, actividades musicales y artísticas, etc. Estuvo acompañada de un folleto no menos importante con las actividades del Festival, programas de conciertos, horarios, y descripciones de las obras, que contemplaron actividades como "experiencias poliartísticas", denominadas "obras", las que consistieron en performances experimentales con alto contenido teatral-literario y de pantomima gestual, cuya base de fondo es la improvisación musical.

Este tipo de "performance" se inscribe dentro de lo que en la década de los 60 eclosionó en el CLAEM, fruto de creadores tan insólitos como Dalila Puzzovio y Marta Minujin, entre los más importantes. Minujin, en un alarde de originalidad sin límites, creó en 1965 un engendro llamado La Menesunda. Consistía en hacer circular al público por una especie de túnel iluminado de cegadoras y destellantes luces de colores. Se caminaba sobre cojines de plástico inflados, plumas de pollo dispersadas por ventiladores, globos con la cara de Marilyn Monroe, reproducciones 
del famoso póster de la artista que creara Andy Warhol, un aviso intermitente de neón violeta de Coca-Cola, cajas de vidrio con abejas vivas hasta que finalmente se encontraba -el visitante- de improviso, con una pareja desnuda en la intimidad de su dormitorio. Echaba mano de lo que se llamó entonces "happening", el "Pop Art" o el "comic", este último con alto contenido erótico e irreverentes sarcasmos efectuados a modo de ejemplo sobre las pinturas de Da Vinci en la Capilla Sixtina. Estas "performances" se apoyaban generalmente en conocidos temas musicales, que podrían abarcar desde Cavalleria rusticana de Mascagni a la música del film de James Bond Agente 007, o desde una monodia gregoriana del siglo XIII a un bolero de Olga Guillot.

Estos espectáculos experimentales y de búsquedas estéticas solían ser interpretados por artistas de la talla de Nacha Guevara, Andrés Gasalla, Norman Brisky y otras importantes figuras escénico-musicales, cuyas fórmulas escenográficas fueron predecesoras de las técnicas digitales de las artes visuales actuales. Por este camino se llegó a extremos tales que no puedo evitar de mencionar una obra audiovisual en formato de "comic" cuyo título era Marvila, la Mujer Maravilla, contra Astra, la Superpilla del planeta Ultra y su Monstruo Destructor, con la música del film del Agente 007 como apoyo. Sin embargo, también existían producciones y estrenos de obras teatrales las que, si bien se inscribían en tendencias como el teatro del absurdo, presumían de una presentación más formal. Tal es el caso del estreno de la notable obra El desatino de la escritora Griselda Gambaro. Toda esta actividad funcionaba entre personas del más alto nivel cultural e intelectual, cuyos conocimientos artísticos en general y musicales en particular, tanto analíticos como instrumentales y formales estaban fuera de toda duda. No se debe olvidar que el célebre conjunto musical Les Luthiers, único en el mundo por la forma de humor a veces brutalmente irrespetuoso y desopilante de encarar la música docta, nació en el Instituto Di Tella en 1967.

Volviendo al festival de junio de 2011. Fueron seis conciertos con obras de cámara y electroacústicas, en el auditorio del Centro Cultural Borges y dos conciertos sinfónicos con la Orquesta Sinfónica Nacional del Teatro Colón en el Auditorio Belgrano, en Avenida Cabildo. Los directores de los conciertos invitados pertenecieron o fueron muy cercanos al CLAEM y realzaron con su excelente desempeño la ejecución de obras de hecho extremadamente difíciles y poco habituales para un público común. Así la labor de un Jorge Sarmientos, de Guatemala, de un Alejo Pérez, invitado de Venezuela, quien finalizó el segundo concierto sinfónico con un homenaje a Ginastera en su frenético Malambo o un jovial y extraordinario músico como Marcelo Delgado, dio interesantísimos frutos al reposicionar ante un público expectante el "background" de una época que si bien es lejana cronológicamente, no se aprecia distanciada notoriamente de la estética actual y contemporánea. Sólo en el área tecnológica se puede advertir con mayor acento los cambios transcurridos en los últimos 50 años, los que, a mi juicio, no han variado sustancialmente en el camino adoptado por las corrientes musicales hoy en día.

En esta perspectiva, los conciertos de cámara incluyeron obras de connotados compositores como Graciela Paraskevaídis, actualmente residente en Uruguay; 
Mariano Etkin, de quien escuchamos también una notable obra sinfónica Música ritual; del colombiano Blas Emilio Atehortúa, el boliviano Alberto Villalpando; Antonio Mastrogiovanni, Lucas Sierra y Alcides Lanza de Argentina, Rafael Aponte-Ledée, de Puerto Rico, y de quien escribe, cuya obra Divertimento para ocho instrumentos fue ejecutada por un destacado grupo de jóvenes intérpretes. Todas estas obras, incluso las electroacústicas, fueron escritas en la década de 1960-1970. Algunas de ellas no habían sido ejecutadas nunca luego de su estreno. Entre las composiciones sinfónicas, llamó la atención el estreno -recién ahora- de ¡Volveremos a las montañas!... del músico chileno avecindado en Barcelona Gabriel Brncic. De gran profundidad conceptual, que mantuvo aún después de 45 años su vigencia así como su dramático uso de efectos orquestales, esta primera versión se remonta en su origen a su estreno oficial en el Teatro Colón, bajo la dirección del maestro Jorge Sarmientos, en 1968, el que debió ser suspendido debido al aviso telefónico de que una bomba explotaría en la platea de la sala. El concierto obviamente se pospuso indefinidamente.

El gran relacionador y por qué no decirlo, el alma de este Festival se constituyó en la persona del compositor argentino Eduardo Kusnir, a quien también le correspondió la tediosa tarea de su compleja organización desde sus primeras luces.

Varias preguntas se posaron sobre lo que fue el Instituto di Tella y su proyección en el tiempo. Entre las interesantes mesas redondas que se realizaron durante los diez días que duró el Festival, aparte de un encuentro inicial entre los ex becarios, presididos por José Luis Castiñeira de Dios, se pueden destacar los temas “¿Qué quedó del CLAEM?;" "Estéticas y valores de las producciones sonoras de los 60. Proyecciones en la actualidad"; "Electroacústicos: ¿elitistas o desclasados?”; "Ginastera en el Di Tella. Correspondencia"; "De transgresiones y perspectivas en el área de música del Di Tella”. Estas ponencias fueron dirigidas y orientadas por altos académicos y licenciados de las Universidades de La Plata, Universidad Nacional de Córdoba, Universidad Nacional de Lanús, Laboratorio de Investigación y Producción Musical Recoleta (continuador del laboratorio del CLAEM) y el Instituto Universitario Nacional de Artes. Estos temas llevaron a replantearse muchas materias en el orden del camino recorrido por la música y que en el Di Tella fueron impulsadas, gracias a la enorme visión y perseverancia de Alberto Ginastera, por figuras tan destacadas como Aaron Copland, Olivier Messiaën, Ricardo Malipiero, Bruno Maderna, Luigi Dallapiccola, Mario Davidovsky, Roger Sessions, Maurice Le Roux, Iannis Xenakis, Luigi Nono, Umberto Eco, Luis de Pablo, entre otros.

Llamó la atención la extraordinaria erudición y conocimientos musicográficos de la musicóloga Amalia (Pola) Suárez Urtubey, en cuyas disertaciones siempre se encontraba algo novedoso e interesante. También dejaron su huella en su paso por la calle Florida 960 hace cincuenta años Astor Piazzolla, y un sorprendente Manzanero, cuyas improvisaciones al piano, su refinada estética musical y sus conocimientos de armonía y contrapunto nos dejaron siempre asombrados. Los técnicos y músicos Fernando von Reichenbach, Mauricio Kröpfl y José Vicente Asuar dieron vida a una fuente inagotable de posibilidades sonoras al laboratorio electroacústico, en ese momento lo más avanzado existente en Latinoamérica. Entre 
las innovaciones ideadas entonces por Mario Davidowsky destacan la posibilidad de usar creativamente el ruido producido por el roce de la cinta magnetofónica, recurso que era controlado mediante un filtro y modelador de anillo, con lo cual podía lograrse una riqueza sonora impresionante. No podemos dejar de citar al extraordinario músico, formidable pianista, improvisador, director y profesor Gerardo Gandini, cuya alma e inusual talento nos llena de admiración, amistad, nostalgia y reconocimientos. De alguna forma, Gandini fue el brazo derecho no solo de Ginastera, sino de todo el Instituto.

También Ginastera trabajó en las selecciones de los becarios con la inestimable ayuda de los destacados compositores chilenos Gustavo Becerra, Alfonso Letelier y León Schidlowsky junto con Lauro Ayestarán de Uruguay y Luigi Dallapiccola quienes conformaron los jurados de admisión para los estudiantes. La compositora argentina Graciela Paraskevaídis afirma en su artículo "De mitos y leyendas" que "el CLAEM, como fragua de la creación musical latinoamericana, no tuvo intenciones ni objetivos de asumir -sea institucional, sea grupalmente- ninguna responsabilidad histórica o ideológica como vanguardia continental de la creación musical; tampoco de embanderarse en la defensa de posiciones políticas o estéticamente radicales". También el compositor argentino Mariano Etkin describe acertadamente lo que sucedía en el Di Tella²: "La sensación predominante era de que todo se podía hacer. También compartieron dos años de sus vidas compositores de disímiles enfoques y estéticas, con las obvias afinidades y rechazos, pero en beneficio del objetivo principal que era acercar los grandes maestros a los jóvenes compositores".

Se podría resumir que el Instituto Di Tella fue en su momento un centro artístico de altísimo nivel, que hizo eclosionar la vanguardia musical en Latinoamérica y la proyectó hacia fines del siglo XX. Queda por descifrar y hacerse la pregunta, que nadie me supo responder en Buenos Aires en el día de hoy: ¿Habría sido el desarrollo de la música en nuestro continente igual como lo es si no hubiese existido el Instituto Di Tella? Dejo su respuesta a la historia. Probablemente en unos 30 años más se podrá apreciar si realmente se abrió entonces una gran ventana o si todo no fue más que un destello llamativo pero aislado en el transcurso de un largo camino.

${ }^{1}$ Graciela Paraskevaídis. "De mitos y leyendas", en José Luis Castiñeira de Dios (director): La música en el Di Tella: resonancias de la modernidad, Buenos Aires: Secretaría de Cultura de la Presidencia de La Nación, 2011, 160 pp. [pp. 50-51].

${ }^{2}$ Mariano Etkin. "Riesgo, dinero y heterodoxia", en Castineira de Dios op. cit. 